\title{
Production of Rice Based Alcoholic Beverages and their Quality Evaluation EVANCE PAKUWAL* and PRAKASH MANANDHAR
}

\author{
Department of Microbiology, St. Xavier's College, Maitighar, Kathmandu, Nepal
}

\begin{abstract}
Murcha is a traditional starter culture used for the production of alcoholic beverages in Nepal. The present study was conducted to compare and characterize rice based alcoholic beverages prepared from varieties of rice as well as starter culture. Optimization of the production was performed using three criteria ( $\mathrm{pH}$, temperature, and Brix). Four different rice varieties (Marsi/ red rice (RR), Black rice, Taichung-176/Taichin, and Khumal-4) and four different cultures (ATCC 18824 /American Type Culture Collection, murcha, yeast isolated from murcha, and commercial wine yeast) were used to prepare rice based alcoholic beverages under optimized condition. The highest acidity was found in black rice (BR) fermented by murcha (2.0 $\pm 0.0 \%)$. The highest alcohol was found in the Taichung-176/Taichin rice fermented by isolated yeast $(23.38 \pm 0.00 \%)$ and wine yeast $(23.38 \pm 0.00 \%)$. The highest antioxidant was found in BR fermented by wine yeast (WY)

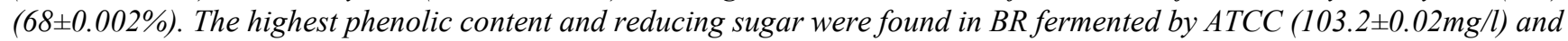
$(1064 \pm 0.03 \mu \mathrm{g} / \mathrm{ml})$ respectively. The study showed different cultures and rice variation gives beverages with different characteristics. The results were subjected to statistical analysis. The result was found to be significant ( $\mathrm{p}<0.05)$.
\end{abstract}

Key words: Rice, Alcohol, Phytochemical, DPPH, Antioxidant, Phenolic content.

\section{Introduction}

Varieties of cereal-based fermented beverages are consumed worldwide (Blandino et al., 2003), which are used for nutritional as well as medicinal purposes (as antiseptic and analgesic). The rice based alcoholic beverages are known to have provided several health-promoting benefits such as antioxidant, anti-hypertensive, anti-diabetes, and anti-cancer activities. They also contain vitamins, minerals, proteins, organic acids, and other nutritional components. Beer, Chyang, Raksi, Sake, Bouza, Pito, and Burukutu are some of the cereal-based alcoholic beverages consumed around the world (Bamforth, 2004; Blandino et al., 2003; Lotong, 1998; Ekundayo, 1969; Bagchi et al., 2016; Karki,1986).

Cereal grains are grown as food crops worldwide. They are considered an important dietary source of carbohydrates, proteins, vitamins, minerals, and fibers. Rice (Oryza sativa) is an important crop and staple food consumed worldwide (Zubair et al., 2015; Mohanty et al., 2012). They are consumed as a food staple and also used as a substrate for fermentation due to their availability (MOAC, 2006). This crop alone contributes to about 40 percent of the total calorie intake (Joshi \& Bauer, 2006). Pigmented rice varieties such as red, black, purple, and brown rice are rich in antioxidant capacity and other bioactive compounds. They were originally consumed in Southeast Asian countries since ancient times (FAOSTAT, 2017). In Nepal, rice is produced in three different zones, Terai and inner Terai (60-900 m), valleys and mid-hills $(1,000-1,500 \mathrm{~m})$, and high hills or mountains (>1,500 m) (MOAC, 2006; Adhikari, 2004).

Murcha is a traditional amylolytic starter culture, which is used to prepare traditional alcoholic drinks in the Himalayan region. There are two types of murcha cakes: manapu and mana. Murcha is composed of various yeasts, molds, and bacteria (Tamang and Sarkar, 1995; Tsuyoshi et al., 2005; Tamang et al., 2012). The microbial cultures used in fermentation are known as starter cultures (Tsuyoshi et al.,
2005; Tamang, 2010), which contain microorganisms responsible for the biochemical and organoleptic modification of the substrate.

Saccharomyces cerevisiae is unicellular yeast, which can ferment sugar to produce ethanol with carbon dioxide and other byproducts. It can withstand stress (ethanol, temperature, acidic environment) and grows rapidly by using sugar effectively (Olowonibi, 2017).

In Nepal, three districts (Kathmandu, Lalitpur, and Bhaktapur), which are in the warm temperate zone are the major areas for obtaining high yields in rice production compared to other districts (FAO, 2004). There were a total of 20 rice varieties released for cultivation in warm and temperate regions of Nepal. Among these, four Taiwanese japonica rice varieties, Taichung-176 rice is one of the semidwarf rice varieties that was introduced in 1950 in Nepal. This variety of rice was chosen because this is consumed widely in Nepal. Khumal-4 (IR-28) is a local rice variety grown in a warm temperate zone. This variety of rice is widely consumed as a part of the main meal in the Nepalese household. Jumli Marsi rice also known as Nepali red rice is a cool temperate rice variety grown in the Mountain region (Joshi and Bauer 2016; Joshi et al 2003; Shrestha 1979). Black rice variety is a newly introduced rice variety in Nepal. It is known that this variety of rice was originally consumed by the rich people or the royals, and it was forbidden to be consumed by the civilians. Therefore, it is also called forbidden rice. It is rich in bioactive compounds such as anthocyanin, antioxidant, phenolic content (Kushwaha, 2016).

The main reasons why these rice varieties were taken for the study were the difference in values of each rice variety. Taichung-176 and Khumal-4 are budget-friendly and widely consumed rice varieties easily found in Nepal. Marsi, and black rice are pigmented rice varieties, which are expensive rice varieties consumed occasionally. Pigmented and non- 
pigmented rice varieties were taken because the study was aimed to compare if the pigments make difference in the quality of fermented rice beverages, and the alcohol content in the beverage.

There are only a few researches conducted to compare the fermented beverages prepared from different cereals in Nepal. While Ray et al 2016 prepared chyang and studied different parameters of the beverage, Thapa et al 2015 conducted a study on readily available cereal-based alcoholic beverages (Distilled) local Raksi and (Non-distilled) Jand, Chhyang, Tumba prepared from rice, wheat, barley, millet, maize, and fruits and studied the ethanol concentration in homebrewed alcohol. As there were no elaborate studies found that involved the study of optimization of the fermentation process and raw materials. This study adds to the readily available information on alcoholic beverages and to understand how different parameters as well as raw materials used can affect the ethanol yield of fermented beverages. The objective of this study was to perform comparative analysis (nutritional, physicochemical, and phytochemical analysis) of rice based alcoholic beverages prepared by using a variety of rice and yeast cultures. The data generated from this research could present the nutritional variation in products prepared from pigmented and non-pigmented rice.

\section{Materials and methods Collection of materials}

Rice varieties (red rice (RR) / Marsi and black rice (BR) and Taichung-176/Taichin and Khumal-4) were bought from the local organic market of Kathmandu, Nepal. Local starter culture (Murcha) was collected from the local market of Asan, Kathmandu. Yeast was isolated from the Murcha. Standard wine yeast (Saccharomyces cerevisiae Var ellipsoids) was obtained from Weingut Gerhard Fünfgeld, Germany) and ATCC culture 18824 Saccharomyces cerevisiae was obtained from the Ministry of Forests and Environment, Department of Biological Sciences, Kathmandu, Nepal.

\section{Isolation of yeast from murcha}

For the isolation of wine yeast from Murcha, serial dilution was performed and plated on potato dextrose agar (PDA). The results were noted after incubating for 72 hours incubation (Sreenath et al., 1986). Microscopic examination was done after performing the gram staining method. The confirmatory tests: Citrate utilization, Sugar utilization (Maltose, Glucose, Fructose, Sucrose and Lactose), flocculation test, Ethanol tolerance test $(10 \%, 13 \%$ and $15 \%)$, Temperature tolerance test $\left(28^{\circ} \mathrm{C}, 37^{\circ} \mathrm{C}\right.$ and $\left.45^{\circ} \mathrm{C}\right)$ were done to confirm the wine yeast. Gram staining was done and observed under the microscope (Guimarães et al., 2006; Ho and Powel 2014; Hassan, 2018).

\section{Optimization of the fermentation process (using three different parameters)}

The Taichung-176 rice was fermented by wine yeast, isolated yeast, and ATCC 18824 during the optimization of the fermentation process. The cooked rice mash was diluted with water to adjust the initial sugar concentration to 15,20 , and $22{ }^{\circ} \mathrm{Bx}$ for process optimization. Different $\mathrm{pH}$ was maintained $3.5,4$, and 5 before fermentation. The $\mathrm{pH}$ was measured by using a $\mathrm{pH}$ meter. The prepared mashes were fermented at two different temperatures maintained at $28^{\circ} \mathrm{C}$ and $30^{\circ} \mathrm{C}$ (Zhan et al., 2003).

\section{Fermentation}

Pre-fermenter cultures of each culture were prepared (ATCC culture S. cerevisiae, standard wine yeast, isolated yeast, and Murcha) by incubating in a shaker incubator for 48 hours (Zhan et al., 2003). The total soluble sugar (TSS) of each substrate was maintained at $20^{\circ}$ Brix as per Pearson's Square Law (Kirk and Sawyer, 1991). Each rice variety was first ground and then cooked for an hour. 0.05\% amylase (source: A. Oryzae) was added to the solution and incubated for 8 hours for saccharification by the method used in Kyalakond (2005) with modifications. It was then filtered and the prefermenter cultures ( $5 \%$ inoculum) were added to each variety of rice and incubated at $28^{\circ} \mathrm{C}$ for 10 days. Finally, the fermented beverages were siphoned to a sterile $750 \mathrm{ml}$ glass bottle and pasteurized. The overall fermentation process was performed according to a study by Chay et al., 2017 with slight modifications.

Physicochemical analysis of rice based alcoholic beverages The TSS, $\mathrm{pH}$, and titratable acidity were determined on each consecutive day during fermentation. The alcohol content was determined at the end of the fermentation by the process of distillation (Manandhar and Sharma, 2013; Ferguson, 2014; AOAC, 2005).

\section{Determination of color and brightness}

Each beverage sample was poured into a glass cuvette and OD was measured. Color intensity was determined by measuring each sample at $420 \mathrm{~nm}$ by using a spectrophotometer. Brightness was determined by adding the reading at $420 \mathrm{~nm}$ and $520 \mathrm{~nm}$ for each sample. The optical density (O.D.) is a logarithmic measurement used for the spectrophotometric absorbance quantification, which shows the percent transmission $(\% \mathrm{~T})$ of light through the sample (Smith and Pokorny, 2009). Absorbance (A) can be represented by the equation:

$\mathrm{A}=\log 10100 / \% \mathrm{~T}$.

\section{Turbidity}

The turbidity of the sample was by pouring $5 \mathrm{ml}$ of each sample in a glass test tube and measuring the reading by using a Turbidity meter. The reading is taken in NTU (Nephelometric turbidity unit) (AOAC, 2005).

\section{Determination of antioxidant activity}

The stock solutions were made by diluting $5 \mathrm{ml}$ beverage with $10 \mathrm{ml}$ of $13.5 \%$ alcohol. Diluted samples of 50, 100, 150, 200, and $250 \mu \mathrm{l}$ were mixed with DPPH $(2500 \mu \mathrm{l})$. Sufficient methanol was added to each sample to obtain a total volume of $3 \mathrm{ml}$. After leaving it for 30 minutes at room temperature, the absorbance was measured at $517 \mathrm{~nm}$. High absorbance of the reaction mixture indicated low free radical scavenging activity (Lugemwa et al., 2013). The capability to scavenge the DPPH radical (\% inhibition) was calculated using the following equation (i):

Inhibition $(\%)=\frac{(A c-A s)}{A c} 100$

where,

$\mathrm{A}_{\mathrm{c}}=$ absorbance of the control (containing $100 \mu \mathrm{l}$ of $\mathrm{MeOH}$ instead of the sample) 
$A_{S}=$ absorbance of the sample (Sripakdee et al., 2015).

\section{Determination of phenolic content}

Total phenol content was based on the Folin-Ciocalteu (FC) method using gallic acid as a standard. $250 \mu$ of diluted FC reagent, and $500 \mu \mathrm{l}$ of saturated sodium carbonate solution was added to $250 \mu \mathrm{l}$ of each of the beverage. The mixture was brought up to $5 \mathrm{ml}$ with distilled water, and the contents were mixed and kept in darkness for $30 \mathrm{~min}$. The mixture was centrifuged at $6000 \mathrm{rpm}$ for $10 \mathrm{~min}$, and the absorbance was read at $725 \mathrm{~nm}$. Blank was prepared by mixing $1.58 \mathrm{ml}$ water and $10 \mathrm{ml} \mathrm{FC}$ with $300 \mathrm{ml} \mathrm{Na}_{2} \mathrm{CO}_{3}$. Blank was measured at a wavelength of $765 \mathrm{~nm}$. The total phenolic content was calculated as gallic acid equivalent using the average molar absorptivity of gallic acid (Kaluza et al., 1980; Singleton et al., 1999; Ragaee et al., 2006).

\section{Determination of reducing sugar}

The reducing sugar was determined by (DNSA) 3, 5dinitrosalicylic acid method according to the procedure by (Shrestha, 2002).

\section{Phytochemical properties of rice-based alcoholic beverages}

Every sample was tested for terpenoid, flavonoid, tannin, protein, saponin, glycoside, and anthraquinone. The methodology for phytochemical analysis was followed according to (Roghini \&Vijayalakshmi, 2018; Bhandari et al., 2019). a. Terpenoid: For the beverage, $3 \mathrm{ml}$ of the sample was mixed with $1 \mathrm{ml}$ chloroform and $1 \mathrm{ml}$ of conc. $\mathrm{H}_{2} \mathrm{SO}_{4}$ was added to the mixture. The sample mixture was observed for color change.

b. Flavonoid: Dilute ammonia $(3 \mathrm{ml})$ was added to $2 \mathrm{ml}$ of each of the samples. $1 \mathrm{ml}$ Conc. $\mathrm{H}_{2} \mathrm{SO}_{4}$ was added to the mixture and color change was observed.

c. Tannin: The sample $(1 \mathrm{ml})$ was added in $4 \mathrm{ml}$ water in test tubes. Few drops of 0.1 percent Ferric chloride were added. It was then observed for the color change.

d. Protein: Each of the beverages $(2 \mathrm{ml})$ was taken in a test tube and $1 \mathrm{ml}$ of $40 \% \mathrm{NaOH}$ solution was added to it. The solution was mixed properly and $1-2$ drops of $\mathrm{CuSO}_{4}$ solution were added to it. Change of color to violet indicates the presence of proteins.

e. Saponin: For beverage, $15 \mathrm{ml}$ of beverage was taken and boiled. The sample which shows the formation of froth indicated the presence of saponin. The formation of froth indicated the presence of saponin.

f. Anthraquinone: The beverage $(10 \mathrm{ml})$ was directly mixed with $0.5 \mathrm{ml}$ ammonia solution (10\%) and mixed properly.

g. Glycoside: The sample $(5 \mathrm{ml})$ was taken in a separate test tube. $2 \mathrm{ml}$ of glacial acetic acid which contains $2 \% \mathrm{FeCl}_{3}$ solution was added to the mixture. $1 \mathrm{ml}$ of concentrated $\mathrm{H}_{2} \mathrm{SO}_{4}$ was added slowly from the side of the wall of the test tube. The formation of the Brown ring indicated the presence of glycoside

Table 1

Physicochemical Parameters of rice based alcoholic beverages

\begin{tabular}{|c|c|c|c|c|c|c|c|c|}
\hline Type of rice & $\begin{array}{c}\text { culture } \\
\text { used }\end{array}$ & Final pH & color (OD) & $\begin{array}{l}\text { Brightness } \\
\text { (OD) }\end{array}$ & $\begin{array}{c}\text { Turbidity } \\
\text { (NTU) }\end{array}$ & $\begin{array}{c}\text { Acidity } \\
\text { (\%) }\end{array}$ & $\begin{array}{c}\text { Alcohol } \\
(\%)\end{array}$ & TSS \\
\hline Taichung-176 & WY & $3.4 \pm 0.03$ & $0.242 \mathrm{~A}$ & $0.458 \mathrm{~A}$ & $96 \pm 0.01$ & $2.0 \pm 0.20^{\mathrm{a}}$ & $23.38 \pm 0.00^{\mathrm{a}}$ & 6 \\
\hline Taichung-176 & IY & $3.5 \pm 0.03$ & $0.144 \mathrm{~A}$ & $0.315 \mathrm{~A}$ & $68 \pm 0.00$ & $1.4 \pm 0.15^{\mathrm{d}}$ & $23.38 \pm 0.00^{\mathrm{a}}$ & 6 \\
\hline Taichung-176 & ATCC & $3.5 \pm 0.00$ & $0.248 \mathrm{~A}$ & $0.472 \mathrm{~A}$ & $74 \pm 0.03$ & $1.3 \pm 0.02^{\mathrm{e}}$ & $19.74 \pm 0.00^{\mathrm{f}}$ & 7 \\
\hline Taichung-176 & Murcha & $3.3 \pm 0.01$ & $0.838 \mathrm{~A}$ & $1.601 \mathrm{~A}$ & $30 \pm 0.00$ & $1.6 \pm 0.02^{b}$ & $20.15 \pm 0.00^{\mathrm{e}}$ & 6 \\
\hline Khumal-4 (KR) & WY & $3.5 \pm 0.00$ & $0.621 \mathrm{~A}$ & $1.138 \mathrm{~A}$ & $92 \pm 0.20$ & $1.3 \pm 0.01^{\mathrm{e}}$ & $16.00 \pm 0.00^{\mathrm{i}}$ & 8 \\
\hline Khumal-4 (KR) & IY & $3.3 \pm 0.00$ & $0.566 \mathrm{~A}$ & $1.043 \mathrm{~A}$ & $42 \pm 0.20$ & $1.5 \pm 0.01^{\mathrm{c}}$ & $\begin{array}{c}17.65 \pm 0.00 \\
\mathrm{~g}\end{array}$ & 7 \\
\hline Khumal-4 (KR) & ATCC & $3.5 \pm 0.02$ & $0.512 \mathrm{~A}$ & $0.964 \mathrm{~A}$ & $36 \pm 0.20$ & $1.5 \pm 0.05^{\mathrm{c}}$ & $12.07 \pm 0.00^{1}$ & 7 \\
\hline Khumal-4 (KR) & Murcha & $3.3 \pm 0.00$ & $0.621 \mathrm{~A}$ & $1.138 \mathrm{~A}$ & $74 \pm 0.20$ & $0.8 \pm 0.01^{\mathrm{h}}$ & $\begin{array}{c}15.34 \pm 0.00 \\
\mathrm{k}\end{array}$ & 6 \\
\hline Black Rice (BR) & WY & $3.6 \pm 0.00$ & $0.480 \mathrm{~A}$ & $0.780 \mathrm{~A}$ & $38 \pm 0.20$ & $1.0 \pm 0.15^{\mathrm{g}}$ & $22.19 \pm 0.00^{\mathrm{c}}$ & 6 \\
\hline Black Rice (BR) & IY & $3.5 \pm 0.02$ & $0.269 \mathrm{~A}$ & $0.459 \mathrm{~A}$ & $36 \pm 0.20$ & $1.6 \pm 0.10^{\mathrm{b}}$ & $\begin{array}{c}22.98 \pm 0.00 \\
b\end{array}$ & 7 \\
\hline Black Rice (BR) & ATCC & $3.5 \pm 0.06$ & $0.120 \mathrm{~A}$ & $0.456 \mathrm{~A}$ & $32 \pm 0.20$ & $1.6 \pm 0.05^{\mathrm{b}}$ & $19.74 \pm 0.00^{\mathrm{f}}$ & 6 \\
\hline Black Rice (BR) & Murcha & $3.4 \pm 0.01$ & $0.263 \mathrm{~A}$ & $0.456 \mathrm{~A}$ & $69 \pm 0.20$ & $2.0 \pm 0.00 \mathrm{a}$ & $\begin{array}{c}20.97 \pm 0.00 \\
\mathrm{~d}\end{array}$ & 5 \\
\hline Marsi (RR) & WY & $3.5 \pm 0.05$ & $0.941 \mathrm{~A}$ & $3.313 \mathrm{~A}$ & $46 \pm 0.00$ & $1.2 \pm 0.03^{\mathrm{f}}$ & $\begin{array}{c}16.41 \pm 0.00 \\
h\end{array}$ & 6 \\
\hline Marsi (RR) & IY & $3.5 \pm 0.03$ & $0.425 \mathrm{~A}$ & $0.822 \mathrm{~A}$ & $32 \pm 0.01$ & $1.5 \pm 0.03^{\mathrm{c}}$ & $15.59 \pm 0.00^{j}$ & 6 \\
\hline Marsi (RR) & ATCC & $3.5 \pm 0.03$ & $0.741 \mathrm{~A}$ & $1.168 \mathrm{~A}$ & $36 \pm 0.03$ & $1.3 \pm 0.05^{\mathrm{e}}$ & $\begin{array}{c}15.34 \pm 0.00 \\
\mathrm{k}\end{array}$ & 10 \\
\hline Marsi (RR) & Murcha & $3.4 \pm 0.01$ & $1.36 \mathrm{~A}$ & $2.406 \mathrm{~A}$ & $41 \pm 0.02$ & $1.3 \pm 0.00^{\mathrm{e}}$ & $15.59 \pm 0.00^{j}$ & 6 \\
\hline
\end{tabular}

NOTE: Color is OD value at $420 \mathrm{~nm}$ and Brightness is the sum of OD values at 420 and $410 \mathrm{~nm}$. Single Values = Mean of Triplicates, $\mathrm{X} \pm \mathrm{Y}=$ Mean \pm S.D of triplicate Values. All the experimental Values were generated three times and the mean was then calculated. Means with different letters in the same column are significantly different. OD = Optical density, A= Absorbance and NTU= Nephelometric turbidity unit.. 


\section{Sensory evaluation}

For the sensory analysis of rice-based fermented beverages, the 9-point Hedonic scale was used. The evaluation was done by a panelist of a total of 10 people in a group (Chay et al., 2017).

\section{Statistical analysis}

The tests were performed on triplicates $(n=3)$. The results are reported as mean \pm standard deviation. The determination of the level of significance of various parameters of different rice varieties was performed by using Minitab Version 18. Two-factor analysis of variance was performed for a completely randomized design to check the level of significance.

\section{Results \\ Isolation of yeast}

Six different isolates (I1-I6) were tested to confirm that the yeast isolated has characteristics of wine yeast. Gram-stained colonies when observed under a microscope, only five were found to be violet in color (budding yeast cells). They were lactose non-fermenting and were able to ferment glucose, sucrose, and fructose. The flocculation test was positive. Five isolates $\mathrm{I} 1, \mathrm{I} 2, \mathrm{I} 3, \mathrm{I} 4$, and $\mathrm{I} 5$ were plated on $28^{\circ} \mathrm{C}, 37^{\circ} \mathrm{C}$, and $45^{\circ} \mathrm{C}$ for temperature tolerance test. Only $\mathrm{I} 2$ showed growth at all three temperatures. Those isolates were plated on YEPD agar consisting of $10 \%, 13 \%$, and $15 \%$ ethanol. Only I2 showed growth at 10,13 , and $15 \%$ for the ethanol tolerance test, and also showed growth during the temperature tolerance test at $28^{\circ} \mathrm{C}, 37^{\circ} \mathrm{C}$, and $45^{\circ} \mathrm{C}$. $\mathrm{I} 2$ had similar characteristics compared to ATCC 18824 and commercial wine yeast. In the carbohydrate fermentation test, a positive result was observed for maltose, dextrose, sucrose, and fructose for I2, standard wine yeast, and ATCC whereas all of these cultures were lactose negative. Hence, it was confirmed to be the best of the wine yeast. The six of the isolates were selected based on the morphological characteristics of the colonies formed, and I6 was not subjected to further analysis after the gram staining because it was gram-negative.

\section{Physicochemical parameters of rice based alcoholic beverages}

Various physicochemical parameters $\mathrm{T}$ ( $\mathrm{pH}$, color, brightness, turbidity, acidity, alcohol, and TSS) were analyzed on the last day of fermentation and given in Table 1. It is found that the highest TSS was found in Khumal-4 fermented by wine yeast $\left(8^{\circ} \mathrm{Bx}\right)$ and the lowest TSS was found in BR fermented by Murcha $\left(5^{\circ} \mathrm{Bx}\right)$. The highest TSS of the beverage fermented by isolated yeast was 7 for Khumal-4 and BR while it was 6 for Taichung-176 and Marsi/RR. The highest acidity was found in BR fermented by Murcha $(0.32 \%)$ and the lowest acidity was found in Taichung-176 fermented by isolated yeast $(0.14 \%)$. The highest alcohol content was found in the Taichung-176 rice fermented by WY and IY cultures, which was $23.38 \%$ for both the beverages.

\section{Bioactive compounds in rice based alcoholic beverages} The highest phenolic content was observed in $(103.2 \pm 0.02 \mathrm{mg} / \mathrm{l}) \mathrm{BR}$ fermented by ATCC. The highest antioxidant was found in Black rice (BR) fermented by WY $(68 \pm 0.00 \%)$ (as shown in Table 2$)$.

Table 2

Bioactive compounds in rice based fermented alcoholic beverages

\begin{tabular}{lllll}
$\begin{array}{l}\text { Type } \\
\text { of rice }\end{array}$ & Culture used & Phenolic content $(\mathbf{m g} / \mathbf{l})$ & Antioxidant $(\%)$ & Reducing sugar $(\boldsymbol{\mu g} / \mathbf{m l})$ \\
\hline Taichung-176 & WY & $77.5 \pm 0.03^{\mathrm{f}}$ & $21 \pm 0.001$ & $286 \pm 0.01^{\mathrm{g}}$ \\
\hline Taichung-176 & IY & $81.5 \pm 0.01^{\mathrm{e}}$ & $16 \pm 0.005$ & $145 \pm 0.00^{\mathrm{p}}$ \\
\hline Taichung-176 & ATCC & $74.3 \pm 0.02^{\mathrm{g}}$ & $16 \pm 0.003$ & $263 \pm 0.02^{\mathrm{k}}$ \\
\hline Taichung-176 & Murcha & $70.2 \pm 0.02^{\mathrm{h}}$ & $17 \pm 0.005$ & $183.71 \pm 0.00^{\mathrm{n}}$ \\
\hline Khumal-4 (KR) & WY & $52.32 \pm 0.00^{\mathrm{n}}$ & $13 \pm 0.001$ & $261 \pm 0.10^{1}$ \\
\hline Khumal-4 (KR) & IY & $46 \pm 0.00^{\mathrm{o}}$ & $10 \pm 0.003$ & $178 \pm 0.001^{\mathrm{o}}$ \\
\hline Khumal-4 (KR) & ATCC & $60.3 \pm 0.01^{\mathrm{k}}$ & $17 \pm 0.001$ & $1032 \pm 0.03^{\mathrm{d}}$ \\
\hline Khumal-4 (KR) & Murcha & $60.1 \pm 0.12^{\mathrm{l}}$ & $21 \pm 0.000$ & $1206 \pm 0.02^{\mathrm{a}}$ \\
\hline Black Rice (BR) & WY & $87.4 \pm 0.00^{\mathrm{c}}$ & $68 \pm 0.002$ & $1074 \pm 0.01^{\mathrm{b}}$ \\
\hline Black Rice (BR) & IY & $82.1 \pm 0.00^{\mathrm{d}}$ & $61 \pm 0.007$ & $974 \pm 0.03^{\mathrm{e}}$ \\
\hline Black Rice (BR) & ATCC & $103.2 \pm 0.02^{\mathrm{a}}$ & $63 \pm 0.002$ & $1064 \pm 0.03^{\mathrm{c}}$ \\
\hline Black Rice (BR) & Murcha & $92.3 \pm 0.00^{\mathrm{b}}$ & $58 \pm 0.004$ & $872.04 \pm 0.02^{\mathrm{f}}$ \\
\hline Marsi (RR) & WY & $63.4 \pm 0.00^{\mathrm{i}}$ & $59 \pm 0.005$ & $264 \pm 0.24^{\mathrm{j}}$ \\
\hline Marsi (RR) & IY & $60.3 \pm 0.02^{\mathrm{k}}$ & $46 \pm 0.003$ & $274 \pm 0.00^{\mathrm{i}}$ \\
\hline Marsi (RR) & ATCC & $62.8 \pm 0.02^{\mathrm{j}}$ & $61 \pm 0.001$ & $247 \pm 0.45^{\mathrm{h}}$ \\
\hline Marsi (RR) & Murcha & $56.5 \pm 0.03^{\mathrm{m}}$ & $42 \pm 0.001$ & $277 \pm 0.25^{\mathrm{k}}$ \\
\hline
\end{tabular}

NOTE: $\mathrm{X} \pm \mathrm{Y}=$ Mean \pm S.D of triplicate Values. All the experimental values were generated three times and the mean was then calculated. Means with different letters in the same column are significantly different. The data presented were found to be statistically significant $(p<0.05)$. 
Table 3

Phytochemical components in rice based alcoholic beverages

\begin{tabular}{clcccccc}
\hline SN & Type of rice & Culture used & Terpenoid & Flavonoid & Tannin & Anthraquinone & Glycoside \\
\hline 1. & Taichung-176 & WY & - & + & - & - & - \\
\hline 2. & Taichung-176 & IY & - & + & - & - & - \\
\hline 3. & Taichung-176 & ATCC & - & + & - & - & - \\
\hline 4. & Taichung-176 & Murcha & - & + & - & - & - \\
\hline 5. & Khumal-4 (KR) & WY & - & + & - & - & - \\
\hline 6. & Khumal-4 (KR) & IY & - & + & - & - & - \\
\hline 7. & Khumal-4 (KR) & ATCC & - & - & - & - & - \\
\hline 8. & Khumal-4 (KR) & Murcha & - & - & - & - & + \\
\hline 9. & Black rice (BR) & WY & + & + & + & + & + \\
\hline 10. & Black rice (BR) & IY & + & + & + & + & + \\
\hline 11. & Black rice (BR) & ATCC & + & + & + & + & + \\
\hline 12. & Black rice (BR) & Murcha & + & + & + & + & + \\
\hline 13. & Marsi $(\mathrm{RR})$ & WY & - & + & + & + & + \\
\hline 14. & Marsi $(\mathrm{RR})$ & IY & - & + & - & - & - \\
\hline 15. & Marsi $(\mathrm{RR})$ & ATCC & - & + & - & - & - \\
\hline 16. & Marsi (RR) & Murcha & - & + & - & - & - \\
\hline
\end{tabular}

Note: $(+)$ denotes positive and $(-)$ denotes negative results.

Phytochemical components in rice based alcoholic beverages

The presence and absence of phytochemical components in different fermented beverages was performed (as shown in Table 3). The terpenoid was present only in Black rice (BR) samples. Anthraquinone, glycoside as well as tannin was found to be present in Black rice (BR) fermented by all the cultures and Marsi rice (RR) fermented by wine yeast. And, flavonoid was present in all beverage combinations except Khumal-4 (KR) rice.

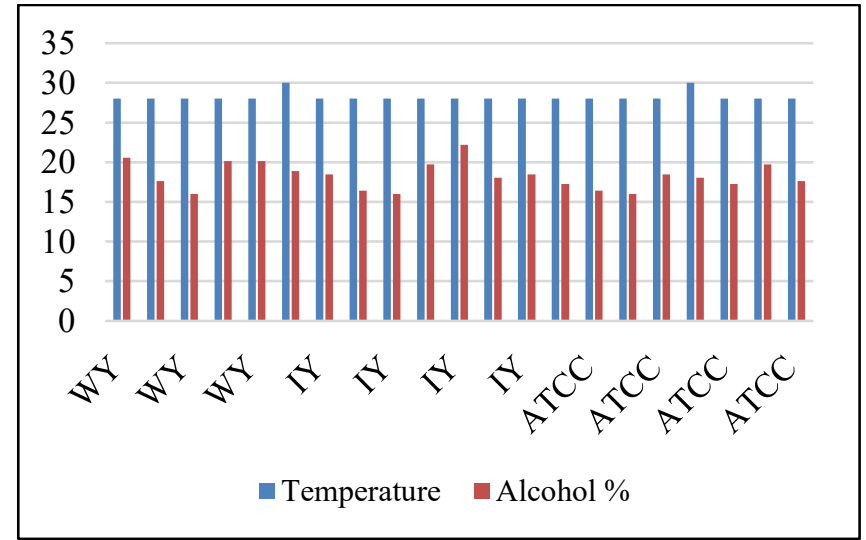

Figure 1a Effect of different temperature on alcohol yield WY-wine yeast, IY-Isolated yeast

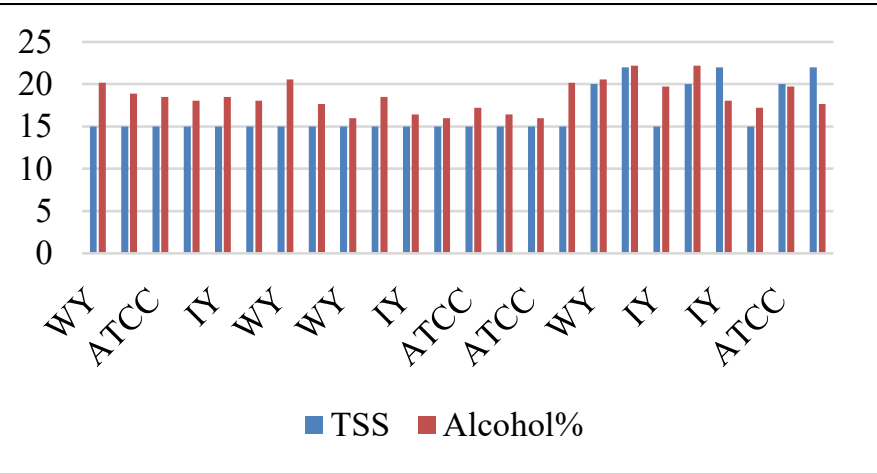

Figure 1b. Effect of different TSS on alcohol yield

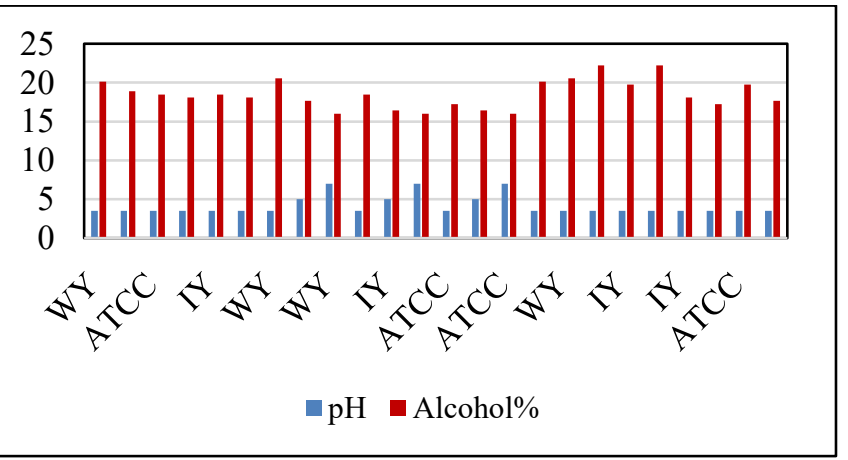

Figure 1c. Effect of $\mathrm{pH}$ on alcohol yield

\section{Sensory Analysis}

All the rice-based beverages were found to be acceptable by all the panelists (as shown in Table 4). The Taichung-176 rice fermented by wine yeast was found to be the most preferred beverage among all the beverages due to its authentic taste. Fermented black rice beverages were found to be the most liked beverages due to the burgundy color developed after fermentation. 
Table 4

Sensory evaluation of rice based fermented alcoholic beverages

\begin{tabular}{|c|c|c|c|c|c|c|c|}
\hline Sample (with code) & Color & $\begin{array}{l}\text { Taste/ } \\
\text { Aroma }\end{array}$ & Attribute & Acceptance & Persistence & Astringency & Mouthfeel \\
\hline Taichung rice fermented by wine yeast (WYT) & 7 & 8.5 & 7.3 & 7 & 8 & 8 & 8 \\
\hline Taichung rice fermented by isolated yeast (IYT) & 7 & 7.5 & 7 & 6.5 & 8 & 7.5 & 8 \\
\hline Taichung rice fermented by ATCC (ATT) & 7 & 8 & 6.5 & 6.8 & 7 & 7 & 7 \\
\hline Taichung rice fermented by Murcha (MT) & 8 & 6.5 & 7 & 6 & 8 & 6.3 & 8 \\
\hline Marsi rice fermented by wine yeast (WYR) & 8 & 7 & 6.3 & 6.5 & 5 & 5 & 6 \\
\hline Marsi rice fermented by isolated yeast (IYR) & 8 & 7 & 6 & 6 & 5.5 & 4.5 & 6 \\
\hline Marsi rice fermented by ATCC (ATR) & 7 & 6.5 & 6.2 & 5.7 & 6 & 5.5 & 5 \\
\hline Marsi rice fermented by Murcha (MR) & 8 & 7 & 6.5 & 6 & 7 & 6 & 6 \\
\hline Khumal-4 rice fermented by wine yeast (WYK) & 7 & 5 & 4.3 & 4.5 & 4 & 4 & 5 \\
\hline Khumal-4 rice fermented by isolated yeast (IYK) & 7 & 6 & 5.2 & 5 & 4.5 & 4 & 5 \\
\hline Khumal-4 rice fermented by ATCC (ATK) & 7 & 5 & 5 & 5 & 4 & 4.5 & 6 \\
\hline Khumal-4 rice fermented by Murcha (MK) & 7 & 5.5 & 5.3 & 5.3 & 5 & 5.2 & 6 \\
\hline Black rice fermented by wine yeast (WYB) & 8 & 7 & 6.5 & 6.5 & 6.5 & 5.8 & 7 \\
\hline Black rice fermented by isolated yeast (IYB) & 8 & 7.5 & 6 & 4.5 & 6 & 5.5 & 6 \\
\hline Black rice fermented by ATCC (ATB) & 8 & 6 & 5 & 4 & 5.5 & 5 & 6 \\
\hline
\end{tabular}

Note: All the scores are means of the scores given by the sensory tasting panel.

Effect of temperature, $\mathrm{pH}$, and TSS on alcohol yield Optimization of the fermentation of rice based alcoholic beverages from Taichung-176 rice was done at different $\mathrm{pH}$ $\left(3.5,5\right.$, and 7), the temperature at $28^{\circ} \mathrm{C}$ and $37^{\circ} \mathrm{C}$, and Brix $\left(15,20\right.$, and $\left.22^{\circ} \mathrm{Bx}\right)$ as shown in Figure 1a-c. The highest alcohol yield was $22.19 \%$ in rice fermented by wine yeast $(\mathrm{pH}$ $3.5,22^{\circ} \mathrm{Bx}$ and $28^{\circ} \mathrm{C}$ ) and $22.19 \%$ in rice fermented by isolated yeast at $28^{\circ} \mathrm{C}\left(\mathrm{pH} \mathrm{3.5)}\right.$ and $20^{\circ} \mathrm{Bx}$. For ATCC, the highest yield was at $15^{\circ} \mathrm{Bx}, \mathrm{pH} 3.5$, and $28^{\circ} \mathrm{C}$, which was $18.48 \%$.

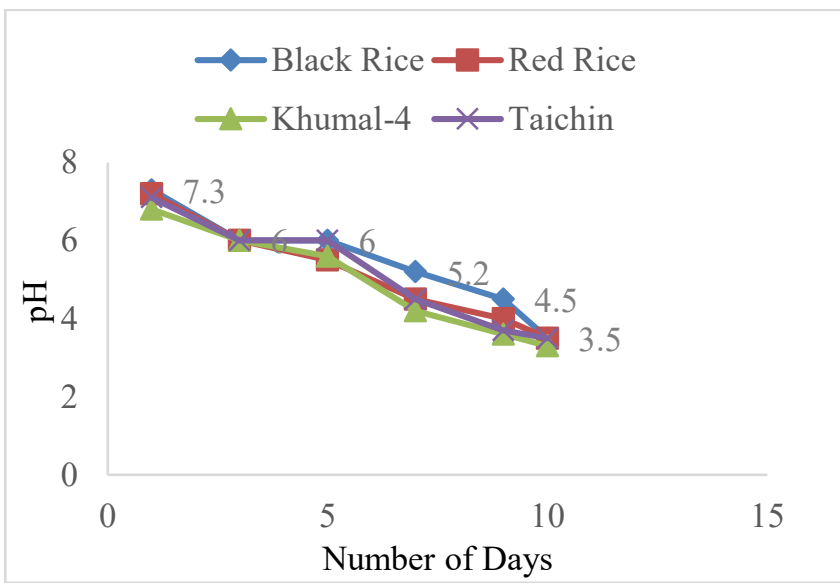

Figure 2a. Change in $\mathrm{pH}$ during fermentation using Isolated yeast

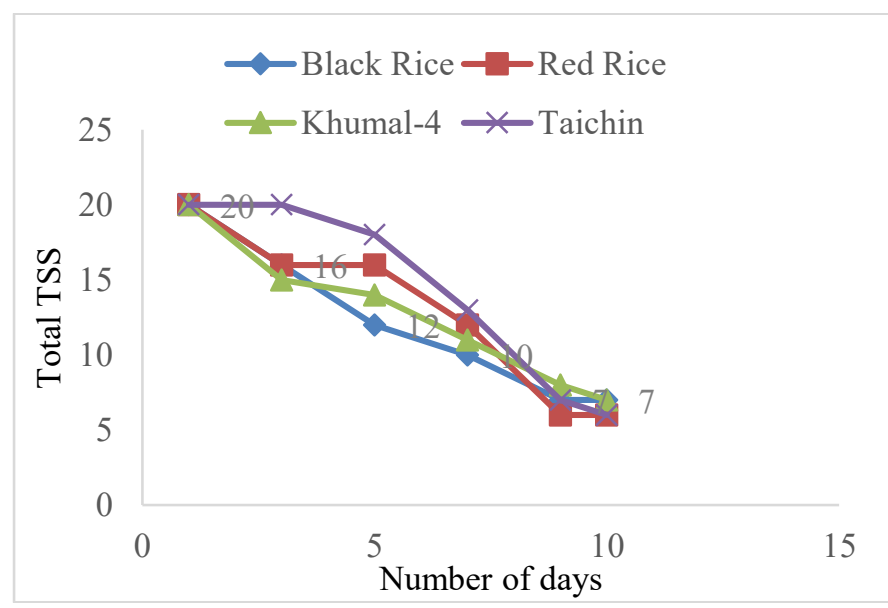

Figure 2b. Change in TSS during fermentation using Isolated yeast

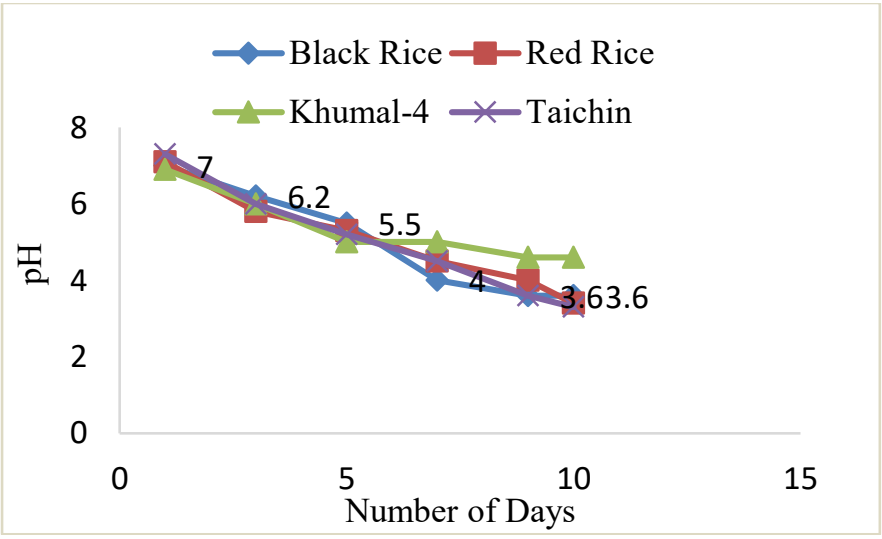

Figure 2c. Change in $\mathrm{pH}$ during fermentation using Wine yeast 


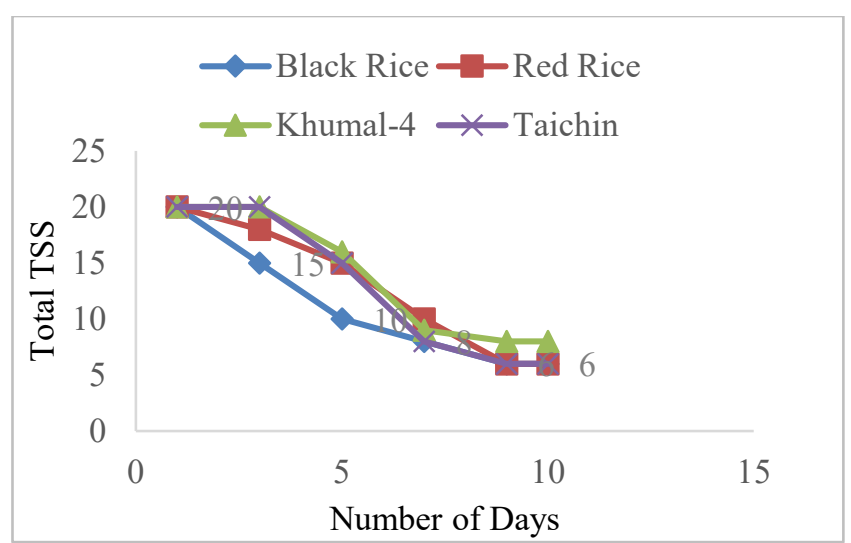

Figure 2d. Change in TSS during fermentation using Wine yeast

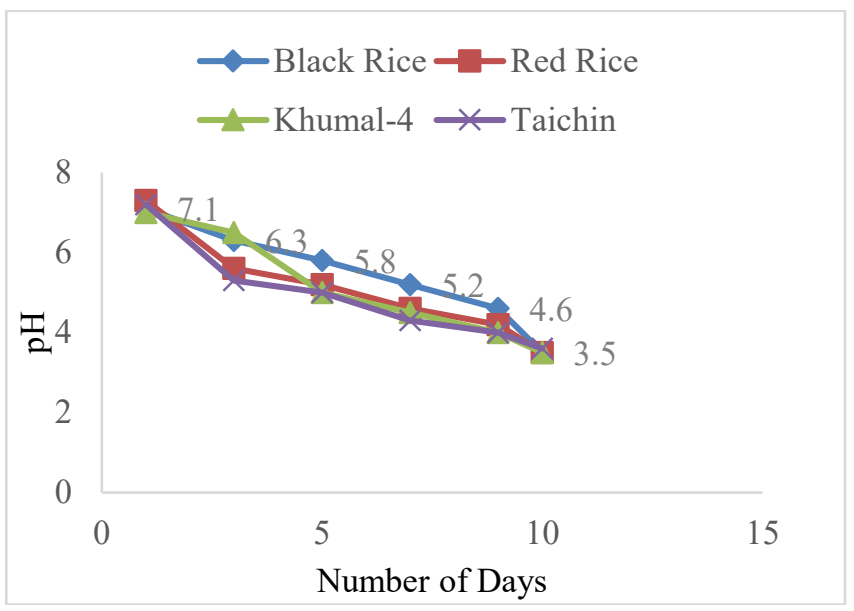

Figure 2e. Change in $\mathrm{pH}$ during fermentation using ATCC 18824 Saccharomyces cerevisiae

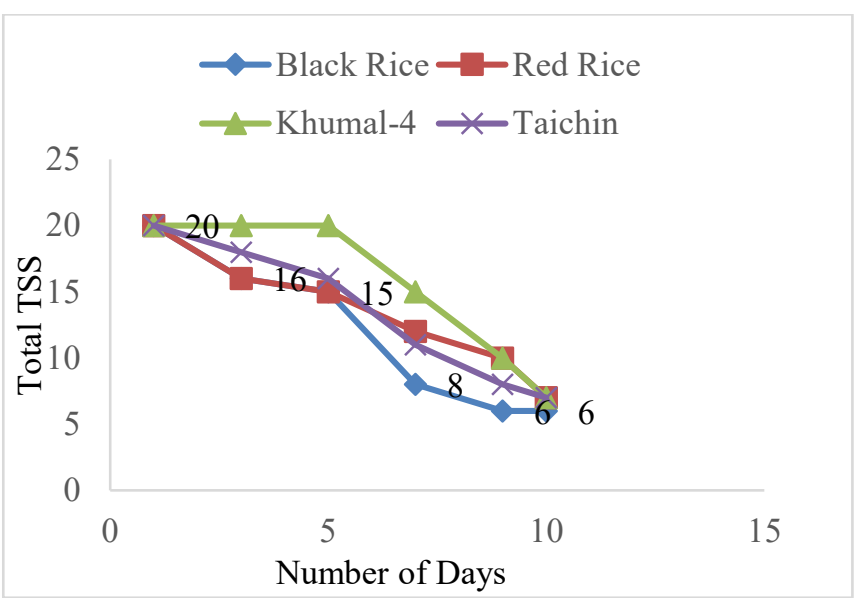

Figure 2f. Change in TSS during fermentation using ATCC 18824 Saccharomyces cerevisiae

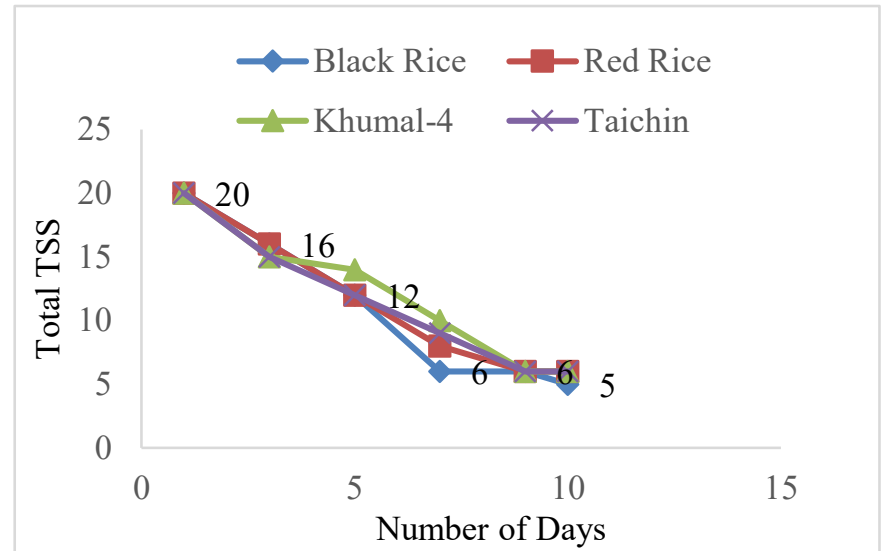

Figure 2g. Change in $\mathrm{pH}$ during fermentation using Murcha

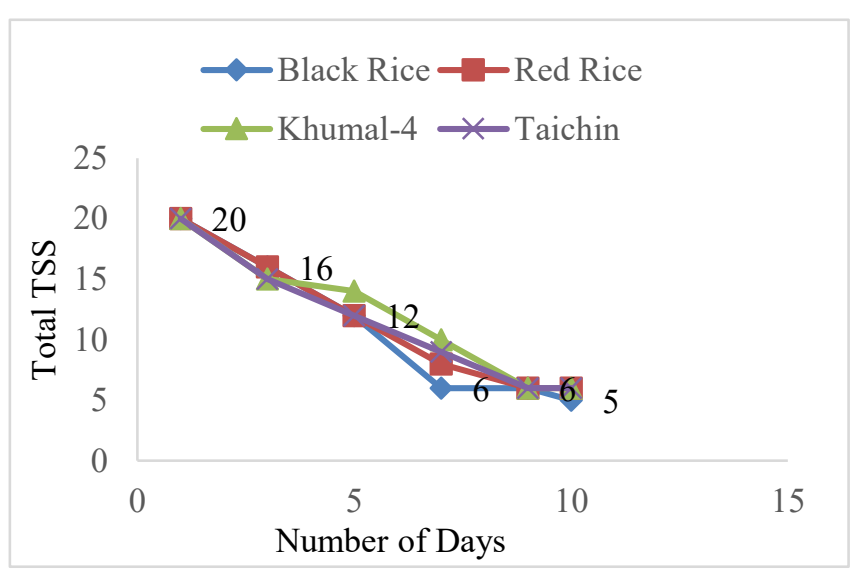

Figure 2h. Change in TSS during fermentation using Murcha

\section{Changes in pH and TSS during fermentation}

The change in $\mathrm{pH}$ and TSS of beverages fermented by different cultures were observed and noted down during the final fermentation process, which is shown in Figure 2 (a-h). The final $\mathrm{pH}$ of the rice based alcoholic beverage fermented by isolated yeast was found to be 3.5 in RR, Taichung-176, and BR (figure 2.a). The highest $\mathrm{pH}$ of the beverage fermented by isolated yeast was found to be 3.5 in RR, Taichung-176, and BR. The lowest was found to be 3.3 in KR (Figure 2.a). The highest TSS of the beverage fermented by isolated yeast was 7 for KR and BR while it was 6 for Taichung-176 and RR (Figure 2.b). The highest and lowest $\mathrm{pH}$ of the beverage fermented by wine yeast was found to be 4 and 3.4 in KR and RR as well as Taichung-176 respectively (Figure 2.c). The highest TSS of the beverage fermented by wine yeast was 8 in Khumal-4 and it was 6 for Taichung-176, $\mathrm{BR}$, and RR (Figure 2.d). The highest $\mathrm{pH}$ of the beverage fermented by ATCC 18824 yeast was found to be 3.6 in Taichung-176 and the lowest $\mathrm{pH}$ was found to be 3.5 in KR, Taichung-176, and BR (Figure 2.e). The highest TSS of the beverage fermented by ATCC 18824 was found to be 7 for Taichung-176, RR, KR and it was 6 for BR (Figure 2.f). The highest $\mathrm{pH}$ of the beverage fermented by Murcha was 4.6 in KR and the lowest was found to be 3.3 in Taichung-176 (Figure 2.g). The highest TSS of the beverage fermented by Murcha was found to be 6 for Taichung-176, KR, and RR while BR had the lowest TSS, which was found to be 5 (Figure 2.h). 
Principal Component Analysis (PCA) of various products developed from culture-rice variation

Principal component analysis (PCA) was performed to estimate the relationships between different parameters of the product and fermentation cultures used for the production of alcoholic beverages. The PCA model was applied to all data to determine the most important variables that explain the relationships between different combinations of alcoholic beverages and to identify any group patterns. Besides, the PCA was performed for each of the rice varieties (Taichung176, Khumal-4, Black rice, Marsi rice) separately. In this study, the loading plot shows the impact of fermentation culture-variation on various parameters of alcoholic beverages, and the score plot shows the dispersion as well as $\%$ variation.

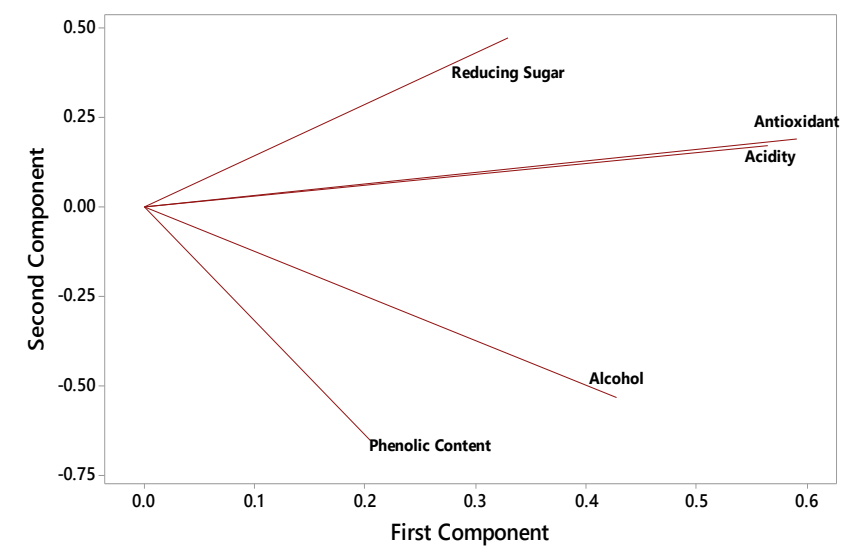

Figure 3a. Loading plot showing correlations of PC with quality parameter in beverages from Taichung-176 rice using different cultures

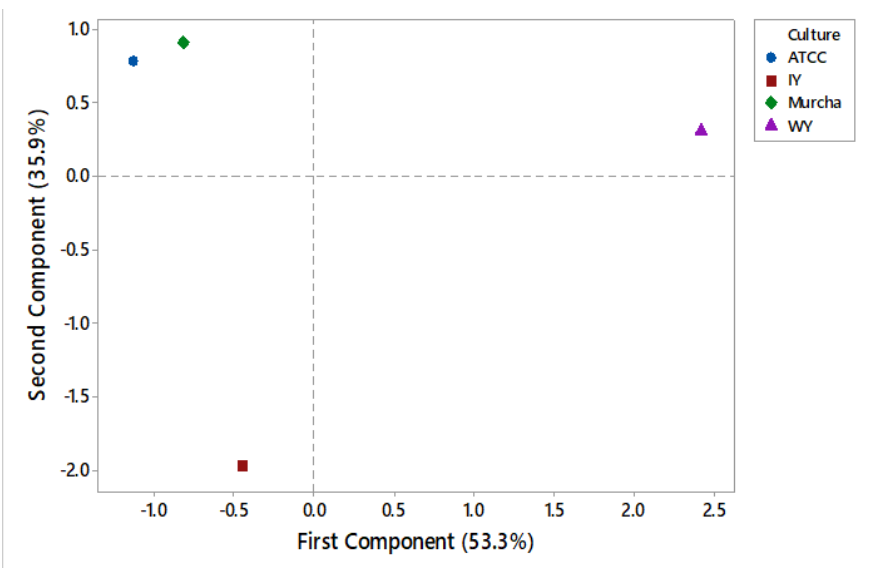

Figure 3b. Score plot of products prepared from TR using various cultures

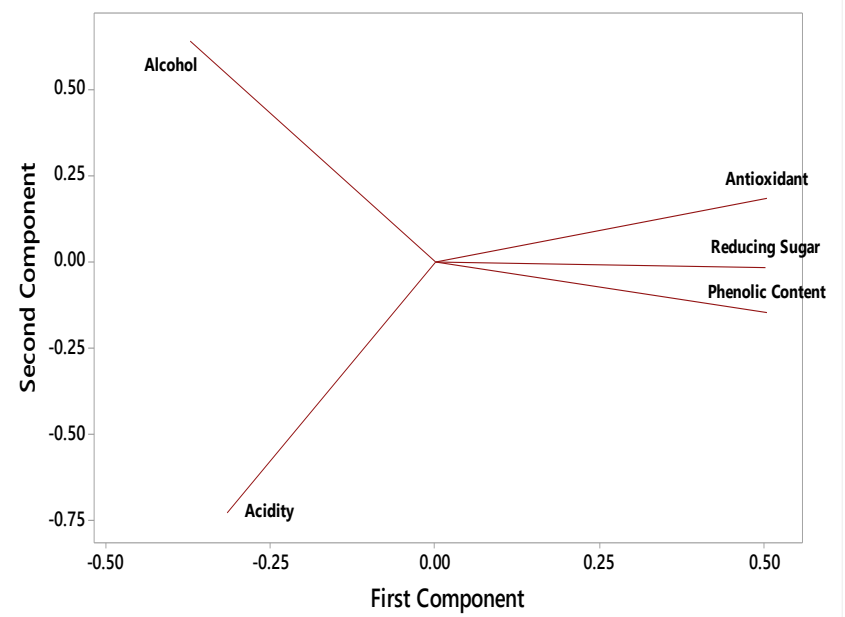

Figure 3c. Loading plot showing correlations of PC with quality parameters in beverages from Khumal-4 rice using different cultures

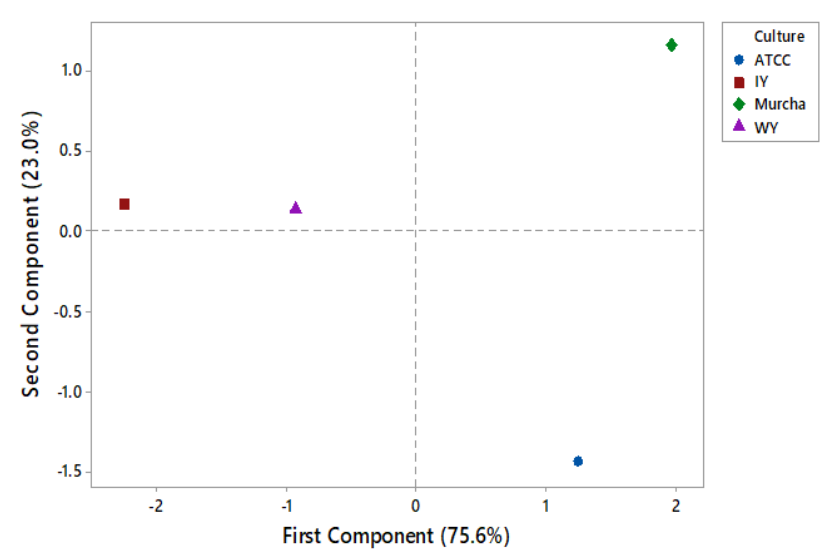

Figure 3d. Score plot of products prepared from KR using various cultures

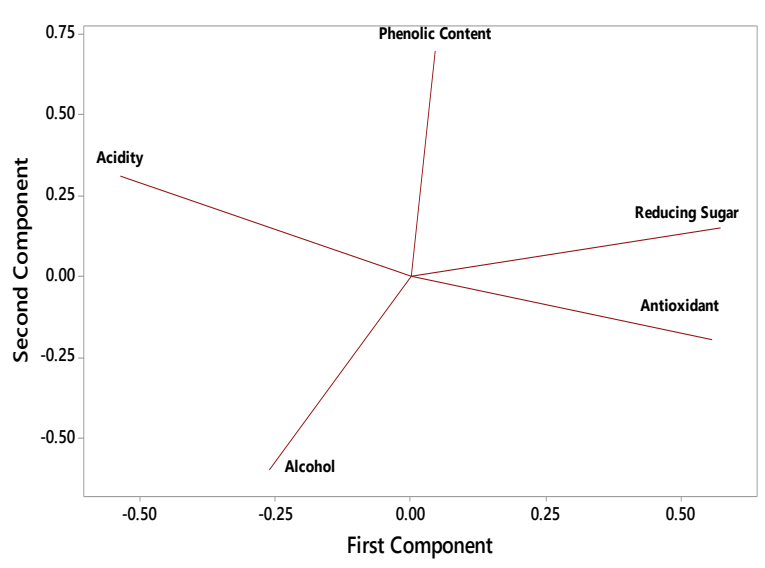

Figure 3e. Loading plot showing correlations of PC with quality parameters in beverages from Black rice using different cultures. 


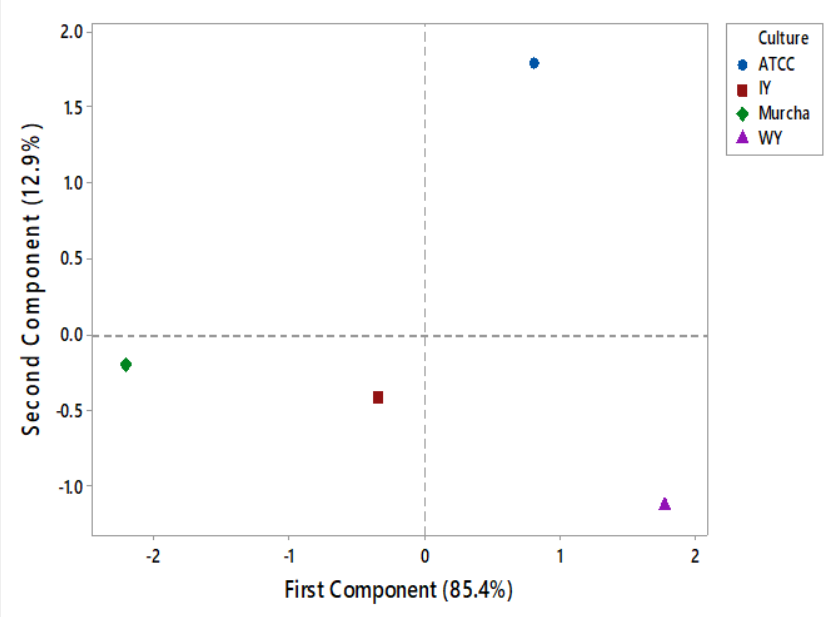

Figure 3f. Score plot of products prepared from BR using various cultures.

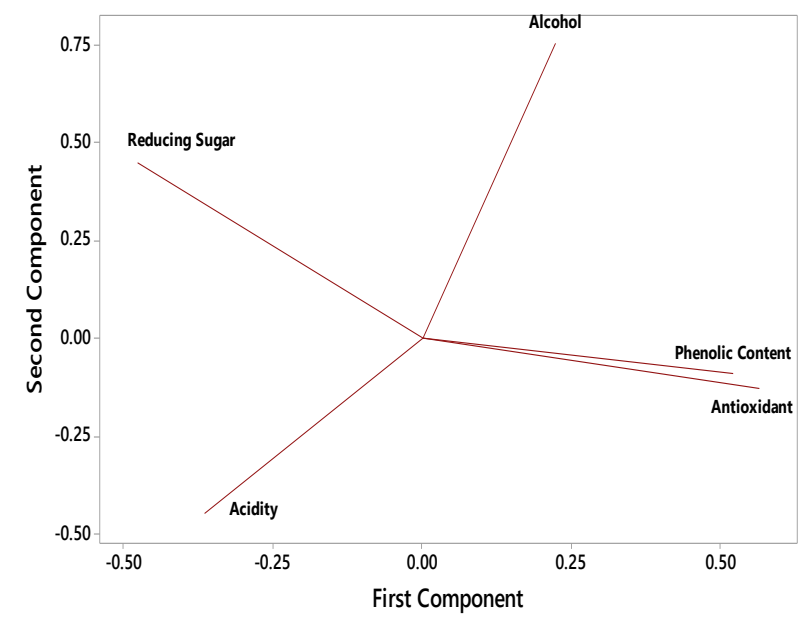

Figure 3g. Loading plot showing correlations of PC with quality parameter in beverages from Marsi/RR using different cultures.

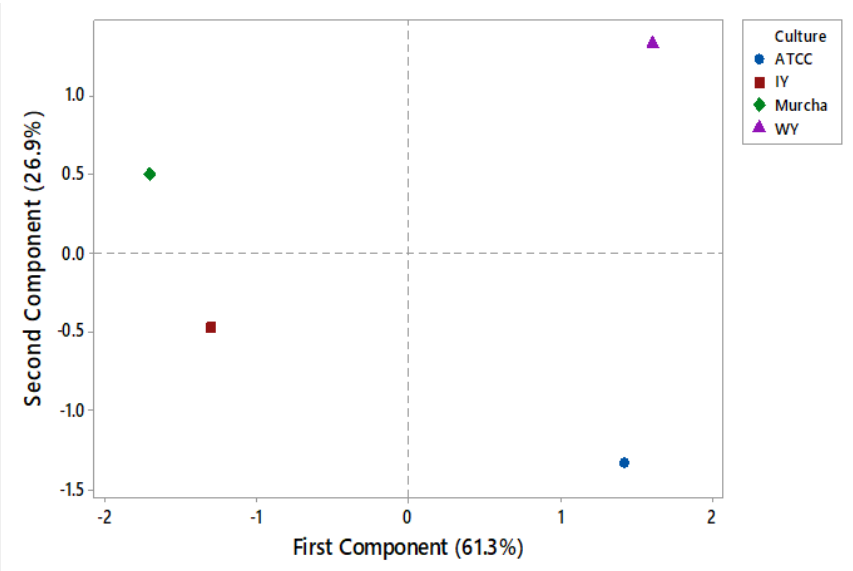

Figure 3h. Score plot of products prepared from RR using various cultures.

Fig. 3(a-h): Principal component analysis of rice based alcoholic beverages prepared by using four different rice varieties and four different cultures.
In figure 3,(a) and 3(b), the sum of principal components PC1 and PC2 explained $89.2 \%$ of the total variations among the Taichung-176 rice fermented beverages prepared from different culture varieties. In this loading plot, Antioxidant, acidity, and reducing sugar have large positive loadings on component 1 , therefore the impact of culture-variation is significant on these parameters. However, Alcohol and phenolic content have large negative loadings on component 2. So, the impact of culture-variation is not significant on these parameters.

In figure 3, from (c) and (d), the sum of principal components PC1 and PC2 explained $98.6 \%$ of the total variations among the Khumal-4 fermented beverages prepared by using different culture varieties. In this loading plot, Antioxidant, phenolic content, and reducing sugar have large positive loadings on component 1 , therefore the impact of culturevariation is significant on these parameters. However, Alcohol and acidity have large negative loadings on component 2. So, the impact of culture-variation is not significant on these parameters.

In figure 3(e) and 3(f), the sum of principal components PC1 and PC2 explained $98.3 \%$ of the variations among the Black rice fermented beverages prepared using different fermentation culture varieties. In this loading plot, Antioxidants and reducing sugar have large positive loadings on component 1 , therefore the impact of culture-variation is significant on these parameters. However, Alcohol and acidity have large negative loadings on component 2 . So, the impact of fermentation culture-variation is not significant on these parameters.

In figure $3(\mathrm{~g})$ and $3(\mathrm{~h})$, the sum of principal components $\mathrm{PC} 1$ and PC2 explained $88.2 \%$ of the total variations among the Marsi/ Red rice fermented beverages prepared from different culture varieties. The loading plot shows that Antioxidant and phenolic content have large positive loadings on component 1 , therefore the impact of culture variation is significant on these parameters. However, acidity and reducing sugar have large negative loadings on component 2 . So, the impact of culture variation is not significant on these parameters.

\section{Discussions}

In this study, a total of 6 different Gram-positive isolates were isolated from the Murcha sample. These isolates showed characteristics similar to $S$. cerevisiae. The sugar assimilation test was performed for the identification of species $S$. cerevisiae using different sugars (Dextrose, maltose, sucrose, lactose, and fructose). From the sugar fermentation test, the 5 isolates showed characteristics of wine yeast. Olowonibi (2017) checked the utilization of sugar, which was indicated by the change in color to pink with gas production. Also, they could not ferment lactose, which is similar to the result of this study. From the ethanol tolerance test, I2 and I3 were found to grow at $28^{\circ} \mathrm{C}, 37^{\circ} \mathrm{C}$ as well as $45^{\circ} \mathrm{C}$. In a study by Ghareib et al. (1988) similar results were seen where the $S$. cerevisiae strains were able to grow at an ethanol concentration of $13 \%$ but inhibited at $14 \%$ ethanol concentration. Arroyo-Lopez et al. (2010) further concluded that the yeast species was able to grow at $11.7 \%$ ethanol concentration. 
In this study, the maximum fermentation was at $\mathrm{pH} 3.5$ followed by $\mathrm{pH} 5$ and then $\mathrm{pH} 7$, and the optimum growth was at $28^{\circ} \mathrm{C}$, followed by $37^{\circ} \mathrm{C}$. Ho and Powel (2014) and Salari and Salari (2017), showed similar results, where ethanol production from $S$. cerevisiae had intensive growth at $\mathrm{pH} 4$ and a temperature range of $25-35^{\circ} \mathrm{C}$. Yalcin and Ozbas (2008) also showed similar results, where the growth of two strains $S$. cerevisiae Kalecik 1 and Narince 3 had optimum growth at $30^{\circ} \mathrm{C}$. Le and Le (2014) observed similar findings, in which growth rate decreased with a decrease in $\mathrm{pH}$ below 5.1 .

In this study, the $\mathrm{pH}$ was observed to be the highest (3.6) in $\mathrm{BR}$ fermented by WY. The final $\mathrm{pH}$ values of rice based alcoholic beverages were within the range of 3.4 to 4.5 (Lee et al. 2007; Seo et al. 2008). Chay et al. 2017 show that the TSS of rice based alcoholic beverages range from $9-18{ }^{\circ} \mathrm{Bx}$, $\mathrm{pH}$ from 3.3-5.0, and alcohol content (13.5-16.0\%), which is similar to the result of this study. As there are different results for different rice varieties fermented by different cultures, this study shows how different rice varieties even when fermented under the same parameters, can have an impact on the amount of ethanol produced.

The highest antioxidant was found in BR fermented by WY (68\%). In similar research (Jeong et al. 2011), the antioxidant in Korean rice wine concentrates was $35 \%-66 \%$, however the results in this study showed a higher concentration of antioxidant content. Higher amounts of antioxidants in the beverages from black rice could be due to the high antioxidant content of the pigmented rice (Kushwaha, 2016).

In this study, the highest reducing sugar was $(1064 \pm 0.03 \mu \mathrm{g} / \mathrm{ml})$ in BR fermented by ATCC culture. A study (Shrestha and Rati, 2002) monitored the fermentation of a traditional beverage (Poko) by analysis of $\mathrm{pH}$, acidity, reducing sugar, and alcohol, which showed the results similar to this study. Another study showed that reducing sugar in rice based alcoholic beverages ranges from $2.5-6.33 \%$ of total sugar (Chay et al. 2017).

During the sensory analysis of rice beverage, each panelist tasted every beverage and found all the beverages were of acceptable quality. The Taichung-176 fermented by wine yeast sample scored highest in taste, mouthfeel, and flavor. Fermented black rice beverages were found to be the most liked beverages based on color. Other studies have shown that fermented pigmented rice beverages develop red color (Koguchi et., al 2010). Similarly, the final product of fermented black rice was red, which can be seen in the photograph.

A study by Norwika et al., (2019) and Destefanis et al., (2000) performed PCA on physicochemical parameters of peach cultivars and characterization of beef respectively. This method was found to be effective for the establishment of a correlation between different characteristics. In this study, PCA was performed to understand how significantly the varieties of cultures used affect the characteristics of fermented beverages from the same rice variety. PCA was found to be effective in finding out the correlation of characteristics with $\mathrm{PC} 1$ and $\mathrm{PC} 2$, and hence helping the interpretation of negative or positive impact on different parameters that determine the quality of the beverages prepared.

The pigmented rice varieties can be used to produce rice based alcoholic beverages, which are also rich in nutrition. The product prepared from different varieties of rice (Red rice/ Marsi, Black rice, Khumal-4, and Taichung-176 rice) can be produced, consumed, and commercialized.

\section{Conclusion}

We can conclude that the highest alcohol content was found in Taichung-176 rice fermented by WY and IY, and the lowest alcohol content was found in Khumal-4 rice fermented by ATCC culture when compared to all the other combinations of rice and culture varieties. From the PCA analysis of different combinations of beverages, we can conclude that the variety of cultures mainly affected the concentration of antioxidants, phenolic content, and reducing sugar in the fermented beverages produced. The score plot showed the distribution of beverages prepared by different cultures but the same variety had a different correlation with the principal components 1 and 2 . We can conclude that the PCA was found to be a very effective method to study how much the fermentation cultures had affected different parameters of alcoholic beverages.

\section{Funding}

This research did not receive any specific grant from funding agencies in the public, commercial, or not-for-profit sectors.

\section{Acknowledgment}

I would like to acknowledge my supervisor, Lecturer Mr. Prakash Manandhar for his constant encouragement, patience, and valuable supervision. I am thankful to our Head of Department, and all the staff members of the Microbiology Department of St. Xavier's College, Maitighar. Finally, I would like to express the deepest gratitude to our family members and friends for their encouragement.

\section{Conflict of Interest}

The authors declare there is no conflict of interest involved.

\section{Ethical Statement}

This article does not contain any studies on human participants or animals performed by any of the authors.

\section{References}

Adhikari, N.P. (2004). Rice research and production in Nepal current status and future direction. Rice research in Nepal. Proceedings of the 24th Summer Crop Workshop, 28-30 June 2004, NARC, NRRP, Hardinath, Dhanusha, Nepal.

AOAC. (2005). Official method of Analysis. 18th Edition, Association of Officiating Analytical Chemists, Washington DC, Method 935.14 and 992.24.

Arroyo-Lopez, F.N., Salvado, Z., Tronchoni, J., Gullamon, J.M., Barrio, E., and Querol, A. (2010). Susceptibility and resistance to ethanol in Saccharomyces strains isolated from wild and fermentative environments. Yeast 27(12):1005-1015.

Bagchi, T.B., Sanghamitra, P., Berliner, J., Chattopadhyay, K., Sarkar, A., Kumar, A., \& Sharma, S.G. (2016). Assessment of physicochemical, functional, and 
nutritional properties of raw and traditional popped rice, Ind. Journal of trad. Knowledg.15: 659-668.

Bamforth, C.W. (2004). Beer: Health and nutrition. John Wiley and Sons.

Bhandari, L., Bista, B.B., Bhatta, M.R., Khanal, C., Khanal, S., Ranjitkar, R., \& Bhandari, D.P. (2019). Phytoconstituents, Antioxidant and Bitterness Value of Swertia chirayita from Four Different Geographical Region of Nepal. J. of Plant Res. 17: 104-111.

Blandino, A., Al-Aseeri, M.E., \& Pandiella, S.S. (2003). Cereal-based fermented foods and beverages. Food Res Int 36: 527-543.

Chay, C., Elegado, F.B., Dizon, E.I., Hurtada, W.A., Norng, C., and Raymundo, L.C. (2017). Effects of rice variety and fermentation method on the physicochemical and sensory properties of rice wine. International Food Research Journal. 24(3): 1117-1123.

Destefanis, G., Barge, M.T., Brugiapaglia, A., and Tassone, S. (2000). The use of principal component analysis (PCA) to characterize beef. Meat Science. 56(3): 255259 ,

Ekundayo, J.A. (1969). The production of pito, a Nigerian fermented beverage. Int J Food Sci Technol 4: 217-225.

FAO. (2004). Food and Agriculture Organization. Sustainable rice-based production and people's livelihood. Int Rice Comm News 52(1): 15-18.

FAOSTAT. (2017). Food and Agriculture Organization of the United Nations. http://www.fao.org/faostat/en/\#data/QC Accessed on 10th December 2019.

Ferguson, J. (2014). Determination of Alcohol Content of Wine by Distillation followed by Density Determination by Hydrometry Chemical Concepts and Techniques.

Ghareib, M., Youssef, K.A., and Khalil, A.A. (1988). Ethanol tolerance of Saccharomyces cerevisiae and its relationship to lipid content and composition. Folia microbiologica 33(6): 447-452.

Guimarães, T.M., Moriel, D.G., Machado, I.P., Picheth, C.M.T.F., \& Bonfilm, T.M.B. (2006). Isolation and characterization of Saccharomyces cerevisiae strains of winery interest. Brazillian Journal of pharmaceutical sciences. 42(1):119-126.

Hassan, L.G., Muhammad, A.B., Aliyu, R.U., Idris, Z.M., Izuagie, T., Umar, K.J., \& Sani, N.A. (2013). Extraction and Characterization of Starches from Four Varieties of Mangifera indica Seeds. IOSR Journal of Applied Chemistry 3(6): pp 16-23.

Ho, D.H.N., and Powel, C. (2014). The effect of temperature on the growth characteristics of ethanol-producing yeast strain. International Journal of Renewable Energy and Environmental Engineering 2: 1-6.

Jae-Wook, Jeong., Pil-Woo, Nam., Seung-Joo, Lee., and Kwang-Geun, Lee. Antioxidant Activities of Korean Rice Wine Concentrates. Journal of Agricultural and Food Chemistry, 201159 (13), 7039-7044. DOI: 10.1021/jf200901.

Joshi, G. R. (2003). Farmers' Perceptions and Decision on Rice Technology Adoption in the Rainfed Eco-system of Nepal: Ph.D. thesis submitted to the University of the Philippines; Los Banos, Philippines.

Joshi, G., \& Bauer, S. (2006). Farmers' Choice of the Modern Rice Varieties in the Rainfed Ecosystem of Nepal. Journal of Agriculture and Rural Development in the Tropics and Subtropics. 107(2), 2006: 129-138.
Kaluza, W.Z., McGrath, R.M., Roberts, T.C., and Schroder, H.H. (1980). Separation of phenolics of Sorghum bicolor (L.) Moench grain. J Agric Food Chem 28: 1191- 1196.

Karki, T. (1986). Some Nepalese fermented foods and beverages. Traditional foods Some Prod Technol 84-96.

Kirk, R.S., and Sawyer, R. (1991). Fermentation products. Pearson's Composition and analysis of foods ( $9^{\text {th }}$ eds). Longman Group Ltd pp 430-438.

Koguchi, Masanori., Saigusa, Noriaki., and Teramoto, Yuji. (2010). Antioxidative Activity of Alcoholic Beverages made from Purple Rice (Oryza sativa var. Indica cv. Shiun). Food Science and Technology Research - FOOD SCI TECHNOL RES. 16. 157-162. 10.3136/fstr.16.157.

Kushwaha, U.K.S. (2016). Black Rice. In Black Rice. Springer. https://doi.org/10.1007/978-3-319-319-3015322.

Kyalakond, Arun. (2005). Studies on preparation of rice wine. Master of Science in Agricultural microbiology. A thesis submitted to the University of Agricultural Sciences, Dharwad.

Le, H.D.T., and Le, V.V.M. (2014). Effects of initial pH value of the medium on the alcoholic fermentation performance of Saccharomyces cerevisiae cells immobilized on nipa leaf sheath pieces. Songklanakarin Journal of Science and Technology 36(6): 663-667.

Lee, C.H. (1995). An introduction to Korean food culture. Korean Am Stud Bull 6 (1): 6-10.

Lee, S.J., Kwon, Y.H., Kim, H.R., and Ahn, B.H. (2007). Chemical and sensory characterization of Korean commercial rice wines (Yakju). Food Science and Biotechnology 16: 374-380

Lotong, N. (1998). Microbiology of fermented foods. Springer, pp 658-695.

Lugemwa, F.N., Snyder, A. L., and Shaikh, K. (2013). Determination of Radical Scavenging Activity and Total Phenols of Wine and Spices: A Randomized Study. Antioxidants 2013. 2: 110-121; doi:10.3390/antiox2030110.

Manandhar, S., Sharma, S. (2013). Practical Approach to Microbiology. 2nd edition, National Book Centre, Kathmandu, 144-213.

MOAC. (2006). Ministry of Agriculture and Cooperatives. Statistical information on Nepalese agriculture 2005/2006 (2062/2063). HMG, MOAC, Agriculture Business Promotion and Statistical Division, Sing Durbar, Kathmandu, Nepal.

Mohanty, S., Wassmann, R., Nelson, A., Moya, P., \& Jagadish, S. V. K. (2012). Rice and climate change: significance for food security and vulnerability. Research Program on Climate Change, Agriculture and Food Security (CCAFS), IRRI.

Nowicka, P., Wojdyło, Aneta., Laskowski, Piotr. (2019). Principal component analysis (PCA) of physicochemical compounds' content in different cultivars of peach fruits, including qualification and quantification of sugars and organic acids by HPLC. European Food Research and Technology. 245:929-938

Olowonibi, O.O. (2017). Isolation and characterization of palm wine strains of Saccharomyces cerevisiae potentially useful as bakery yeasts. European Journal of Experimental Biology 7(11). 
Penh, P. (2017). Effect of rice variety and fermentation method on the physiochemical and sensory properties of rice wine. 24(June): 1117-1123.

Ragaee, Sanaa., Abdel-Aal, El-Sayed., and Noaman, Maher. (2006). Antioxidant activity and nutrient composition of selected cereals for food use. Food Chemistry. 98. 32-38. 10.1016/j.foodchem.2005.04.039.

Ray, S., Bagyaraj, D.J., Thilagar, G., and Tamang, J.P. (2016). Preparation of Chyang, an ethnic fermented beverage of the Himalayas, using different raw cereals. Journal of Ethnic Foods. 3(4): 297-299.

Roghini, R., and Vijayalakshmi, K. (2018). Phytochemical screening, quantitative analysis of flavonoids and minerals in ethanolic extract of Citrus paradisi. Int $J$ Pharm Sci \& Res 9(11): 4859-64.

Salari, R., \& Salari, R. (2017). Investigation of best Saccharomyces cerevisiae growth condition. Electronic physician 9(1):3592-3597.

Sanchez, P.C., Ramirez, T.J., and Velasco, A.C. (1985). Evaluation of the fermentation efficiency and traditional bubod for rice wine fermentation. Philippine Agricultural Scientist 68(4): 483-491.

Seo, D.H., Jung, J.H., Kim, H.Y., Kim, Y.R., Ha, S.J., Kim, Y.C., \& Park, C.S. (2007). Identification of lactic acid bacteria involved in traditional Korean rice wine fermentation. Food Science and Biotechnology 16: 994 998.

Shrestha, K.P. (1979). Report on rice breeding for cold tolerance materials. Proceedings of the 5th Rice Improvement Workshop held at the Department of Agriculture, Nepal, 27 Feb-2 March 1978.

Shrestha, B. (2002). Practical biochemistry and biotechnology. SNEMP, Swoyambhu, Kathmandu pp 35-40.

Shrestha, H., and Rati, E.R. (2002). Microbiological profile of murcha starters and physico-chemical characteristics of poko, a rice based traditional fermented food product of Nepal. Food Biotechnol 16:1-15.

Singleton, VL., Orthofer, R., \& Lamuela, R.M. (1999). Analysis of total phenols and other oxidation substrates and antioxidants by means of Folin-ciocalteu Reagent. Methods in Enzymology 299: 152-178.

Smith, Vivianne., and Pokorny, Joel. (2003). Color Matching and Color Discrimination. The Science of Color. 10.1016/B978-044451251-2/50004-0.

Sreenath, H.K., Chapman, T.W., and Jeffries, T.W. (1986). Ethanol production from D-xylose in batch fermentations with Candida shehatae: process variables. Appl Microbiol Biotechnol 24:294-299.

Sripakdee, T., Sriwicha, A., Jansam, N., Mahachai, R., and Chanthai, S. (2015). Determination of total phenolics and ascorbic acid related to antioxidant activity and thermal stability of the Mao fruit juice. Int. Food Res. J. 22: 618624 .

Stikic, R., Djordje, G. Mirjana, D. Biljana, V.R. Zorica, J. Dusanka, M.O. Sven, E.J. Mirjana, M. (2012). Agronomical and nutritional evaluation of quinoa seeds (Chenopodium quinoa Willd.) as an ingredient in bread formulations. Journal of Cereal Science, 55: 132-138.

Tamang, J.P. (2010). Himalayan fermented Foods. CRC Press Taylor and Francis Group. USA. 187-227.
Tamang, J.P., and Sarkar, P.K. (1995). Microflora of murcha: an amylolytic fermentation starter. Microbios 81:115122.

Tamang, J.P., Tamang, N., Thapa, S., Dewan, S., Tamang, B., Yonzan, H., and Kharel, N. (2012). Microorganisms and Nutritional value of ethnic fermented foods and alcoholic beverages of North East India. Indian Journal of Traditional Knowledge, 11(1):7-25.

Taninura, W, Sanchez PC and Kozaki M (1977). The fermented food in the Philippines I. Tapuy (rice wine). Journal of Agriculture 22:118-134.

Thapa, N., Aryal, K. K., Paudel, M., Puri, R., Thapa, P., Shrestha, S., Shrestha, S., \& Stray-Pedersen, B. (2015). Nepalese Homebrewed Alcoholic Beverages: Types, Ingredients, and Ethanol Concentration from a NationWide Survey. Journal of Nepal Health Research Council, 13(29), 59-65.

Tsuyoshi, N., Fudou, R., \& Yamanaka, S. (2005). Identification of yeast strains isolated from marcha in Sikkim, a microbial starter for amylolytic fermentation. Int J Food Microbiol 99:135-146.

Turkut, G.M., Hulya, C., Seher, K., and Sebnem, T. (2016). Effect of quinoa flour on gluten-free bread batter rheology and bread quality. Journal of Cereal Science, 69: 174-181.

Valcárcel-Yamani, B., and Lannes, S.D.S. (2012). Applications of quinoa (Chenopodium quinoa Willd.) and amaranth (Amaranthus spp.) and their influence in the nutritional value of cereal based foods. Food and Public Health, 2(6): 265-275.

Yalcin, S.K., and Ozbas, Z.Y. (2008). Effects of pH and temperature on growth and glycerol production kinetics of two indigenous wine strains of Saccharomyces cerevisiae in mixed cultures with Kluyveromyces lactis on high sugar fermentation. Microbiological research. 169(2): 907-914.

Yo-shimoto, Y., Egashira, T., Hanashiro, I., Ohinata, H., Takase, Y., and Takeda, Y. (2004). Molecular structure and some physicochemical properties of buckwheat starches. Cereal Chemistry. 81: 515-520.

Zeladaa, C.R.E., Vasco, C. Fernando, M. Jose, A.T. Ursula, G.B. (2018). Combined effect of xanthan gum and water content on physicochemical and textural properties of gluten-free batter and bread. Food Research International, 111: 544-555.

Zhan, X., Wang, D., and Tuinstra, M.R. (2003). Ethanol and lactic acid production as affected by sorghum genotype and location. Ind Crops Prod 18.

Zubair, M.A., Rahman, M.S., Islam, M.S., Abedin, M.Z., and Sikder, M.A. (2015). A Comparative study of the proximate composition of selected rice varieties in Tangail, Bangladesh Department of Food Technology and Nutritional Science.Department of Biochemistry and Molecular Biology 8(2): 97-102. 